\title{
Reflection 2008: The State of Science, Religion and Consciousness
}

\author{
Huping $\mathrm{Hu}$ \\ (Dated: December 16, 2008)
}

\begin{abstract}
2008 is a year in which the world's economical, financial and even political systems are going through unprecedented turmoil and earth-shaking transformations. Yet, it seems that nothing has changed in Science except that many scientists are sadly loosing there jobs and/or funding. Religion also seems to be stagnant with the exceptions that various hastened prophecies of 2012 are flourishing and charitable contributions are in drastic declines. Under these historical, uncertain, sad but hopeful circumstances, it is appropriate and even urgent that we further reflect on the state of Science and Religion. It is also appropriate that we reflect on the state of consciousness research because our state of consciousness is the catalyst for the transformation of humanity at the dawn of 2012 and the missing link on the pass to truth.
\end{abstract}

Key Words: 2008, 2012, reflection, science, religion, consciousness, state

\section{Universality by Rumi}

What can I do, Submitters to [truth]? I do not know myself. I am neither Christian nor Jew, neither Magian nor Muslim, I am not from east or west, not from land or sea, not from the shafts of nature nor from the spheres of the firmament, not of the earth, not of water, not of air, not of fire.

I am not from the highest heaven, not from this world, not from existence, not from being. I am not from India, not from China, not from Bulgar, not from Saqsin, not from the realm of the two Iraqs, not from the land of Khurasan. I am not from the world, not from beyond, not from heaven and not from hell. I am not from Adam, not from Eve, not from paradise and not from Ridwan.

My place is placeless, my trace is traceless, no body, no soul, I am from the soul of souls. I have chased out duality, lived the two worlds as one. One I seek, one I know, one I see, one I call. He is the first, He is the last, He is the outer, He is the inner. Beyond "Him" and "He is"I know no other.

I am drunk from the cup of love, the two worlds have escaped me. I have no concern but carouse and rapture. If one day in my life I spend a moment without [Him], from that hour and that time I would repent my life. If one day I am given a moment in solitude with [Him], I will trample the two worlds underfoot and dance forever. O Sun of Tabriz, I am so tipsy here in this world, I have no tale to tell but tipsiness and rapture (Source: Wikipedia.) 


\section{Introduction}

On February 18, 2008, I finished an essay entitled "We Have a Dream" by borrowing and synthesizing the famous words of Thomas Jefferson, Abraham Lincoln and Martin Luther King, Jr. The essay calls for and predicts drastic changes in the sacred enterprises of science and religion in the spirit of these great men. The essay appeared in this journal (Hu, 2008). Some might have asked: Who am I to make that call? The answer: Nobody, just a regular human being and a submitter to truth as Rumi would say.

Little did I know that Giordano Bruno, advocate of Copernican theory, was burned at stake 408 years ago on February 17, 1600. Nor could any of us have known or predicted that 2008 is a year in which the world's economical, financial and even political systems are going through unprecedented turmoil and earthshaking transformations and Americans have just elected Barack Hussein Obama as our President.

On the other hand, none of the changes called for and predicted in the essay has occurred as could be expected. In this respect, I have so far failed miserably as a "prophet" of change in science and religion. Indeed, it seems that nothing has changed in science. It is business as usual with the exceptions that many scientists (in that matter, even the so called "quants" on Wall Street) are losing theirs jobs and/or funding and the LHC (Large Hadron Collider) had a disastrous start. Similar, there seems no progress in Religion with the exceptions that charitable contributions are in drastic declines and various hastened prophecies of 2012 are flourishing.

Under these historical, uncertain, sad but hopeful circumstances, it is appropriate and even urgent that we further reflect on the state of science and religion. It is also appropriate that we reflect on the state of consciousness research because our state of consciousness is the catalyst for the transformation of humanity at the dawn of 2012 and the missing link on the pass to truth.

Corresponding author: Huping Hu, Ph.D., J.D.

Address: QuantumDream, Inc., 25 Lubber Street, Stony Brook, NY 11790, USA.

e-mail: hupinghu@quantumbrain.org
One may again ask: What qualifications do I have for writing such reflection? While for one thing, I have been in the trenches of scientific studies of consciousness over the past nine years as a biophysicist and outsider unencumbered by academic conformity and orthodoxy. So, perhaps I have something useful to say. When I say "scientific", I mean building concrete and testable models of consciousness connected to hard sciences (e.g., physics, neuroscience, biochemistry and physiology) and doing the experimental testing. I and my collaborator have done both.

\section{The State of Science}

I wish that I could say "the state of science is strong" but I cannot. Instead I couldn't stop thinking how the modern scientific enterprise, especially theoretical physics in the establishment, seems to be near the brink of intellectual and moral bankruptcy. Indeed, many others from both inside and out the academia have expressed similar feelings. This status of affairs has also been clearly reflected in two recent books "The Trouble with Physics" (Smolin, 2006) and "Not Even Wrong" (Woit, 2006). Sadly, while being able to point out what is wrong with the currently still fashionable string theory of the establishment, the writers of these two books seem not to be able to see either the forest or the tree because perhaps they themselves are perpetually lost in a desert of nowhere.

Thus, I would like to offer here my own views on how the establishment has ended up in this situation. One of the popular explanations for a prolonged stagnant period of a particular field such as theoretical physics is that genius only comes along once in a while. Max Planck (1936) once said that "[n]ew scientific ideas never spring from a communal body, however organized, but rather from the head of an individually inspired researcher who struggles with his problems in lonely thought and unites all his thought on one single point which is his whole world for the moment." However, even to accept this explanation to be somewhat true, most of us have to admit our own mediocrity and have the courage to change by becoming humble, open-minded and willing to hear alternative theories and opposing views. The sad 
fact is that this is very hard to do because of human nature.

Instead, some of us in the field, on the one hand, worship past geniuses by elevating their theories and discoveries to absolute truths (dogmas) and, on the other hand, treat any alternative theories or views as crackpot theories or worse. When more and more individuals having influences and/or controls over research funding, research direction, hiring of scientists, graduate programs and undergraduate programs do these things, the stagnant field enters into a vicious cycle of further stagnancy and mediocrity. Even worse, when these individuals themselves are elevated to the status of living geniuses and enthroned onto prominent positions, chairs and titles, they exercise even greater power to the greater detriment of the already stagnant field and science overall.

One of the glaring examples of this kind is the current situation surrounding superstring theory which attempts to unify the Standard Model of particle physics with Einstein's General Theory of Relativity ("GTR") in the face of many complaints that the latter is inconsistent and is likely invalid. There are indeed numerous experimental data including our own ( $\mathrm{Hu} \& \mathrm{Wu}$, 2006b) suggesting that GTR is likely wrong. Under these circumstances, logic and prudence call for careful reexaminations of GTR as a viable theory instead of blind faith in GTR. What one hopes to achieve by unifying Standard Model and GTR if the latter is wrong? Isn't that GTR is invalid the reason why it couldn't be unified with the Standard Model so far despite several decades of efforts by countless physicists?

On the darker and sinister side, many individuals in the modern science enterprises treat science not as an arena of truth-seeking but a place of livelihood, business and other personal gains. The goal for them is not about truth but themselves. These individuals create so much of the unhealthy atmosphere in science such as rivalry, protectionism, hypocrisy, commercialism and suppression and intolerance of alternative views which directly lead to mediocrity and stagnancy in science.

The damages have been staggering. First, generations of young scientists have been brain washed with and forced into establishment science. This is perhaps the greatest damage and most unfortunate. Second, available governmental and private funds have been misallocated and wasted. Third, certain areas of science, especially theoretical physics, have become not only distorted but also inaccessible to common people in contrary to one of the sacred goals of science which is to enlighten the mass.

Similarly, being the mouthpieces and servants of the establishment sciences, the mainstream science journals and electronic archives reject almost everything which does not meet establishment's approval, although they speak of freedom and impartiality of scientific journalism. In so doing, they have perverted editorial screening and peer-review from impartial screening and review into instrumentations of suppression by the establishment and double-layered veil for themselves to hide their hypocrisy and servitude to the establishment.

In addition, in mainstream sciences the study and even the mentioning of mind or consciousness are till taboo and indeed the physicists' version of a theory of everything does not include consciousness. However, physicists encountered consciousness more than eighty years ever since quantum mechanics was born (see, e.g., Rosenblum \& Kuttner, 2006). Instead of embracing such encounters and exploring the mystery of consciousness, the majority of physicists have been avoiding the consciousness issue like a plague.

The irony is that, if we cannot understand ourselves and refuse to do so, how can we hope to understand fundamentally the world surrounding us. Isn't the logic should be that in order to understand the external world fundamentally we need also (or we must first) understand how consciousness work? How can one call one's theory a theory of everything if everything is not included?

\section{The State of Religion (and Spirituality)}

"Science and religion are two windows that people look through, trying to understand the big universe outside, trying to understand why we are here. The two windows give different views, but they look out at the same universe. Both views are one-sided, neither is complete. 
Hu, H., Reflection 2008: The State of Science, Religion and Consciousness

Both leave out essential features of the real world. And both are worthy of respect. Trouble arises when either science or religion claims universal jurisdiction, when either religious or scientific dogma claims to be infallible. Religious creationists and scientific materialists are equally dogmatic and insensitive. By their arrogance they bring both science and religion into disrepute. The media exaggerate their numbers and importance. The media rarely mention the fact that the great majority of religious people belong to moderate denominations that treat science with respect, or the fact that the great majority of scientists treat religion with respect so long as religion does not claim jurisdiction over scientific questions." These are the views of Freeman Dyson (2000) on the current state of science and religion. I couldn't agree more.

More than 800 years ago the great Sufi poet Rumi in his poem Universality citied at the beginning gave mankind a glimpse, through the spiritual and poetic window, of a higher consciousness from a GOD eye view. What Rumi described resonates with many earlier spiritual teachings and some religious writings. Rumi's descriptions were also refined or reflected in the work of subsequent scholars with or without knowledge of Rumi's work and regurgitated by many others with or without credit or understanding. One such later scholar in the $20^{\text {th }}$ century is the little known American mystical philosopher Franklin Merrell-Wolff whose aphorism of Consciousness without an Object, which unknowingly shows up in our writings as Prespacetime, is cited at the end of this essay.

The fact is that, spiritually, GOD and the nature of consciousness have been well studied and well understood over the millenniums by the spiritually enlightened and many scholars of various religious traditions, although most of us never recognize or admit it due to our own ignorance or arrogance.

It seems to me that traditional religions are at the present stagnant or even in decline and they must evolve and transform in this golden age of science just as science must evolve and transform to reconcile with religion and spirituality. That is, various religions must incorporate scientific ideas and facts into them.

\section{The Way Out of the Crisis}

One may now asks how can the currently depressing and even shameful situations be turn around? First, all men and women of science and religion have to rise above themselves by putting their personal interests and gains aside and the business of truth-seeking as the first priority. Second. All truth-seeking men and women should be granted the rights of freedom, equality and opportunity to be heard in the pursuit of truth. Third, all men and women of science and religion should be humble, openminded and tolerant of alternative and opposing views. Fourth, all students in science should be exposed to not only mainstream scientific theories and views but also alternative and minority theories and views.

Over the last 450 years since Copernicus, we have reached the golden age of science to the great detriment of spirituality. It is now up to us, the modern scientists, theologian and all truth-seeking men and women, to study the nature of consciousness scientifically, reveal GOD scientifically and further advance and transform both science and religion so as to reconcile and unify them and usher mankind into a new era of unprecedented enlightenment and knowledge.

It is with this candid spirit and a heavy but open heart that we shall in our forthcoming papers offer a possible outsider solution towards a theory of everything which shall include consciousness, gravity and even spirituality. In a sense, I am forced to attempt this feat. I left science as soon as I completed my Ph.D. in 1991. I went into business, law school, Wall Street and now private law practice. But I was pulled back to science in 2000 and have not left since. Maybe it is my fate but I cannot help to wonder why an outsider has to get involved.

I recall that even recently I privately begged some physicists including one of my colleagues to come up with a mathematical formulation of gravity based on our experimental findings on gravity. But so far I only hear silence. I have also, both at conferences and in private, suggested, begged and encouraged many to repeat our experiments and a few indeed did promise to do just that but again so far we hear silence. I know that it cannot be that our results are uninteresting. 
Well then, what is the reason? Is that our results being said to be bizarre by an apparently ignorant conference reporter the reason (Faw, 2007)? Or is that our experiments were done in the basement of our home, with ourselves and our adult family members as guinea pigs in some of the experiments, and in our spare times? If the reason would be the latter, the ones who would think that way but possess modern research laboratories and research funds should be ashamed of themselves.

\section{The State of Consciousness Research}

"As a man who has devoted his whole life to the most clear headed science, to the study of matter, I can tell you as a result of my research about atoms this much: There is no matter as such. All matter originates and exists only by virtue of a force which brings the particle of an atom to vibration and holds this most minute solar system of the atom together. We must assume behind this force the existence of a conscious and intelligent mind. This mind is the matrix of all matter." These were the words of Max Planck (1944). Planck (1931) had also concluded that "I regard consciousness as fundamental. I regard matter as derivative from consciousness. We cannot get behind consciousness. Everything that we talk about, everything that we regard as existing, postulates consciousness"

However, as we are told by the authors of a recent book "Quantum Enigma - Physics Encounters Consciousness" that most physicists today still avoid consciousness like a plague (Rosenblum \& Kuttner, 2006). Indeed, this has been the situation since 80 years ago when quantum mechanics was born. The authors explain that this sad situation is understandable to some degree because physicists like to work with hard sciences (Id.). In contrast, consciousness does not enter quantum physics through the deterministic and unitary Schrödinger equation but apparently operates from outside space-time through free will. Further, as the authors justifiably imply, the field of consciousness studies is infested with selfappointed authorities, pseudo-scientists and "snake oil" promoters who give the field a bad reputation and scare physicists away (Id.).
However, it is my view that there are no legitimate excuses whatsoever for physicists and other scientists not exploring the mystery of consciousness and its connections to quantum physics.

Substantively, the authors in their book succinctly summarize nine interpretations of quantum physics and point out in no uncertain terms that every interpretation encounters consciousness ( $/ d$.). They agree with Bell's view that quantum mechanics is so far correct on everything it predicts but incomplete (Id.). Like the authors, I full-heartedly agree with Bell's view based on the findings of our own research.

I am of the view that the state of consciousness research is rapidly changing and the future promising. My current thinking is that the reality is an interactive quantum reality centered on consciousness and the interaction between consciousness and reality seems to be a "chicken-egg" problem. The perplexing questions are: (1) Is quantum reality (the "chicken") produced and influence by consciousness (the "egg"); or (2) is consciousness produced and influenced by quantum reality? It is well known that this type of dilemma occurs when one searches for a first cause which is circular.

Many quantum mind researchers have tried to answer parts of these two questions. For example, on the first question, Henry Stapp (1993) has made heroic efforts in the face of various criticisms. However, the question of how consciousness influences the brain or through what quantum entities inside the brain is the brain being influenced is far from settled. To say the least, Stapp's theory needs to be mapped to the correct quantum entities being influenced by consciousness in the brain. On this, Stapp so far takes the "high road". In our theory, the quantum entities are the nuclear and/or electron spins in neural membranes and proteins (Hu \& Wu, 2002). The only way to get the correct mapping is to put various models to experimental tests which so far are few and far in between.

On the other hand, since a conscious observer is made of quantum entities, the second and reverse question should also be asked, answered and reconciled with the first question. On this, Roger Penrose and Stuart 
Hameroff (1996), for example, have made tremendous efforts in producing and advocating the Penrose-Hameroff model which proposes a specific mechanism in the brain based on noncomputability, quantum gravity and tubulins in microtubules. Penrose and Hameroff are admirable for taking the "low road" with the risk of being ridiculed. Penrose's arguments for the non-computability of conscious process are quite impressive and strong. But only experiments can tell whether his bold speculation of quantum gravity being the objective cause of wave function collapse ("OR") makes any sense. Even if the experiments would be successful, it is still a far cry from proving tubulins in microtubules are involved in consciousness as Hameroff suggests.

Many people feel that Hameroff's idea is misguided and Penrose got on the wrong "OR" boat, so to speak, not only because neural electrochemical activities occur in and around neural membranes but also the simple, tubular and uniform structures of microtubules make them unlikely to be the carriers of information related to consciousness. By the way, we have demonstrated experimentally that gravity is likely the manifestation of quantum entanglement ( $\mathrm{Hu} \& \mathrm{Wu}, 2006 \mathrm{~b})$. Thus, in my opinion, the role of gravity in consciousness is more likely to achieve binding and wave function collapse is associated with disentanglement.

Philosophically, David Chalmers (1996) in the 90's shook up the field of consciousness studies with his classification of the problems of consciousness into "easy problems" and "hard problems". But mere classification in itself will only redefine the problems not provide any solutions. The essence of Chalmers' work are that: (1) reductive explanations of consciousness in terms of physical processes are invalid; and (2) conscious experiences are as primary as mass, charge and spacetime and thus entail new psychophysical principles which treat information as having both a physical aspect and phenomenal aspect (Id.). Chalmers is admirably a rare and clear-headed dualist who irks materialists and perhaps others by his ideas and (some would say) arrogance.

It is my view that Chalmers' first point is only valid with respect to classical physical processes but not quantum processes which are fundamentally psycho-physical. With respect to the second point, I can agree that consciousness is primary but I take that experiences are informational contents not properties or entities. Further, it seems that Chalmers is skeptical about the connections of quantum mechanics and consciousness. This is inexplicable and rather unfortunate.

Of course, there are also deep philosophical questions associated with consciousness. Einstein once stated that "I like to think that moon is there even I am not looking at it" (see, e.g., Rosenblum \& Kuttner, 2006). Then, there is the old question "If a tree falls in the forest with no one around to hear it fall, is there any sound?" (Id.). To answer these fundamental questions, we need to reconcile the "chickenegg" problems of consciousness and reality raised earlier.

Borrowing from certain philosophy of Hinduism which resonate deeply with MerrellWolff's aphorism cited at the end of this essay, I am inclined to believe that: (1) Consciousness is both transcendent and immanent, that is, the transcendental aspect of consciousness produces and influences reality as the interactive output of consciousness and, in turn, reality produces and influences immanent aspect of consciousness as the interactive input to consciousness; and (2) Human consciousness is a limited or individualized version of this dualaspect consciousness such that we have limited free will and limited observation/experience which is mostly classical at macroscopic levels but quantum at microscopic levels.

As a limited transcendental consciousness, we have through free will the choice of what measurement to do in a quantum experiment but not the ability to control the result of measurement. That is, the result appears to us as random. On the other hand, at the macroscopic level, we also have the choice through free will of what to do but the outcome, depending on context, is sometimes certain and at other times uncertain. Further, as a limited immanent consciousness, we can only observe the measurement result in a quantum experiment which we conduct and experiences the macroscopic environment surrounding us as the classical world. 
Hu, H., Reflection 2008: The State of Science, Religion and Consciousness

Applying this dual-aspect consciousness ontology, we would respond to Einstein with the answer that the moon would still be there even if he was not looking at it because it is produced or influenced by the (unlimited) transcendental consciousness and observed or experienced by the (unlimited) immanent consciousness. Similarly, the answer to the old question would be that there are still sound heard by the (unlimited) immanent consciousness.

Finally, I would like to point out that the Dirac equation contains the "mysterious" quantum spin which forms the key basis of our spin-mediated consciousness theory ( $\mathrm{Hu} \& \mathrm{Wu}$, 2002). In my opinion, this is the equation holding one of the major keys to a genuine science of consciousness and may be called the "God Equation" as shall be shown elsewhere in due time.

\section{Changes Demanded By Experiments}

Over the last 80 years from the time quantum mechanics was born to the present, there have been countless experiments which repeatedly show an observer-created reality at the microscopic levels (Rosenblum \& Kuttner, 2006). This is known as the measurement problem in physics. Since the early 80 's to the present, there are also numerous experiments which confirm that quantum entanglement is physically real (Id.). Although there are many interpretations, the experimental results themselves are all undisputed and predicted by quantum mechanics (Id.).

The fact is that the connections between quantum mechanics and consciousness are real and tangible not just pseudoscience or New Age mumbo-jumbo. Hopefully, physicists and all other scientist in the academics shall break away from the invisible "prison" of conformity and orthodoxy and turn the perplexing questions in quantum mechanics into golden opportunities for solving the mystery of consciousness.

On our part, we have found ways to test our spin-mediated consciousness theory experimentally, since conscious brain functions necessarily involve information ( $\mathrm{Hu} \& \mathrm{Wu}, 2006 \mathrm{a}$ \& 2006b). We found that applying magnetic pulses to the brain when an anesthetic was placed in between caused the brain to feel the effect of said anesthetic as if the test subject had actually inhaled the same (Hu \& Wu, 2006a). We further found that drinking water exposed to magnetic pulses, laser light or microwave when an anesthetic was placed in between also causes brain effects in various degrees (Id.). Through additional experiments, we verified that the said brain effect was indeed the consequence of quantum entanglement ( $(d$.). These results defy common belief that quantum entanglement alone cannot be used to transmit information and support the possibility of a quantum brain.

Experimenting with simple physical systems such as water quantum-entangled with water being manipulated, we further found nonlocal chemical, thermal and gravitational effects (Hu \& Wu, 2006b). We found that the pH value, temperature and gravity of a liquid such as water in the detecting reservoirs can be nonlocally affected through manipulating water in the remote reservoir (Id.). These non-local effects are all reproducible, surprisingly robust and further support a quantum brain theory such as our spin mediated consciousness theory (Id.). They can be used for non-local signaling and many other purposes. We again suggest that they are mediated by quantum entanglement between nuclear and/or electron spins in the treated liquids $(/ d$.).

Perhaps the most shocking is that we have experimentally demonstrated Newton's instantaneous gravity and Mach's instantaneous connection conjecture and the relationship between gravity and quantum entanglement (Id.). Our findings also imply that the properties of all matters can be affected non-locally through quantum entanglement mediated processes. Second, the second law of thermodynamics may not hold when two quantum-entangled systems together with their respective local environments are considered as two isolated systems and one of them is manipulated. Third, gravity has a non-local aspect associated with quantum entanglement thus can be non-locally manipulated through quantum entanglement mediated processes. Fourth, in quantum- entangled systems such as biological systems, quantum information may drive such systems to a more ordered state against the disorderly effect of environmental heat. 
Hu, H., Reflection 2008: The State of Science, Religion and Consciousness

On a more fundamental level, our findings shed new lights on the nature and characteristics of quantum entanglement and gravity, reveal the true conflict between quantum theory and Einstein's theories of relativity, provide vital clues for resolution of the measurement problem, and support non-local hidden variable based theories such as Bohmian mechanics and a non-local cosmology.

In short, the above experiments call for drastic changes in our understandings of nature, consciousness and life.

\section{Closing Remarks}

In the year 2000 the beginning of the New Millennium, I, a submitter to truth, humbly embarked on the mission of scientific study of consciousness with my collaborator.

This mission made me to realize in 2003 that the GOD in whom we trust should be spiritual as well as scientific in this golden age of science. In other word, GOD has to be known or revealed scientifically, if GOD does exist. This also means that science itself must also evolve and eventually unify with religion which itself must evolve. So, since then I have also embarked on the mission of searching for a scientific GOD. Indeed, since we are all made out of the same subatomic, atomic and genetic alphabets, the scientific GOD each of us seeks should be one and the same whatever our race, religion and other differences.

During the course of these missions, I have encountered the work of intellectual and spiritual giants those of whom I discovered so far I am honoring through Scientific GOD Prize which to some may appear nakedly arrogant. However arrogant, I ask that my fellow truthseekers judge me by our deeds not by appearance.

In his controversial book "The End of Science" published right before the turn of the New Millennium, science writer John Horgan (1996) argued that we might now "fac[e] the limits of knowledge in the twilight of the scientific age." I, on the other hand, believe that human knowledge and understanding of Nature and Life will probably always be provisional and approximate. Therefore, there will be no end to science and the pursuit of truth. We will always be able to make progress in science and get closer and closer to absolute truth. However, as Thomas Kuhn (1962) pointed out, science makes major progress through paradigm shift. I believe that we are at the threshold of a rebirth of science and religion.

From a mystical point of view, one may even argue that Horgan (1996) was foretold what will come in the New Millennium but he either chose to be the messenger of gloom and doom of science or failed to be a "prophet" of the coming rebirth of science and religion. One only needs to read his Epilogue entitled "the Terror of God" in his book to see the basis for such speculation: "Years ago...I had...a mystical experience. Subjectively, I was hurtling through a dazzling; dark limbo toward what I was sure was the secret of life. Wave after wave of acute astonishment at the miraculousness of the existence washed over me. At the same time, I was gripped by overwhelming solipsism. I became convinced...that I was the only conscious being in the universe. There was no future, no past, no present other than what I imagined them to be. I was, initially filled with a limitless joy and power. Then, abruptly, I became convinced that if I abandon myself further to this ecstasy, it might consume me. If I alone exist, who could bring me back from oblivion? Who could save me? With this realization my bliss turned into horror; I fled the same revelation I had so eagerly sought. I felt myself falling through a great darkness, and as I fall I dissolved into what seemed to be an infinity of selves" (Id.). Rumi would likely be ecstatic about this instead of being terrified.

The selfish, jealous and/or sarcastic ones among us may ask: Whose paradigm will it be? Will it be mine, his or yours? In so asking, they either fail or don't want to see that truth is not a possession or property and a paradigm belongs to all of us even if a single person discovered it!

Now, if I would assert that "scientific GOD exists and I am His/Her prophet", I would appear shameless, delusional and extremely arrogant. Or am I? Here I again urge my fellow truth seekers to judge me by our deeds not by what I assert. Our deeds are contained in the work we already done and in our forthcoming papers to be completed and published. Every genuine truth seeker is welcomed to judge our deeds. 
Hu, H., Reflection 2008: The State of Science, Religion and Consciousness

My conviction is that all of us can be the "prophets" of a scientific GOD by doing genuine and hard scientific and spiritual work in the pursuit of truth. The differences will only be in qualities and quantities. Ironically, aren't some among us claiming expressly or implicitly that they themselves are the prophets or gods of science?

In our forthcoming papers, we shall try to realize in concrete and scientific terms the spiritual and philosophical insights of the intellectual and spiritual giants such as Rumi, Planck and Merrell-Wolff cited in this essay by attempting the feat of laying down an ontological foundation for a genuine theory of everything which shall include consciousness, gravity and even spirituality.

If we succeed, it shall be all the better for all truth-seeking men and women because everyone can then move on with the real business of constructing a theory of everything. If we would fail, we would shed no tear and have no regret knowing that we have done our best. We would then probably try again. However, in the former case let no one in science become the subject of Planck's agony and irony that "[a] new scientific truth does not triumph by convincing its opponents and making them see the light, but rather because its opponents eventually die, and a new generation grows up that is familiar with it" (Planck, 1949).

In closing, let us remind ourselves the proverb that "the [truth] is in the details". To eventually arrive at a genuine science of consciousness, we must build and experimentally test various concrete models of consciousness which are connected to hard sciences. And to eventually transform, reconcile and unify science and religion, all truth seekers must work together in the pursuit of truth. All of us in science and religion must rise above ourselves. The new era of enlightened human existence critically depends on each of us truth seekers to shape. Whether mankind shall advance or perish and whether good shall overcome evil is determined by the future state of our consciousness because it is the catalyst for the transformation of humanity at the dawn of 2012 and the missing link on the pass to truth.
Consciousness Without An Object (Prespacetime) by Franklin Merrell-Wolff

1. [Prespacetime] is. 2. Before objects were, [Prespacetime] is. 3. Though objects seem to exist, [Prespacetime] is. 4. When objects vanish, yet remaining through all unaffected, [Prespacetime] is. 5. Outside of [Prespacetime] nothing is. 6. Within the bosom of [Prespacetime] lies the power of awareness that projects objects. 6. When objects are projected, the power of awareness as subject is presupposed, yet [Prespacetime] remains unchanged. 7. When consciousness of objects is born, then, likewise, consciousness of absence of objects arises. 8. Consciousness of objects is the Universe. 9. Consciousness of absence of objects is Nothingness. 10. Within [Prespacetime] lie both the Universe and Nothingness, yet to [Prespacetime] these two are the same. 11. Within [Prespacetime] lies the seed of Time. 12. When awareness cognizes Time then knowledge of Timelessness is born. 13. To be aware of Time is to be aware of the Universe, and to be aware of the Universe is to be aware of Time. 14. To realize Timelessness is to attain Nothingness. 15. But for [Prespacetime] there is no difference between Time and Timelessness. 16. Within [Prespacetime] lies the seed of the worldcontaining Space. 17. When awareness cognizes the world-containing Space then knowledge of the Spatial Void is born. 18. To be aware of the world-containing Space is to be aware of the Universe of Objects. 19. To realize the Spatial Void is to awaken to Nirvanic Consciousness. 20. But for [Prespacetime] there is no difference between the world-containing Space and the Spatial Void. 21. Within [Prespacetime] lies the Seed of Law. 22. When consciousness of objects is born the Law is invoked as a Force tending ever toward Equilibrium. 23. All objects exist as tensions within [Prespacetime] that tend ever to flow into their own complements or others. 24. The ultimate effect of the flow of all objects into their complements is mutual cancellation in complete Equilibrium. 25. Consciousness of the field of tensions is the Universe. 26. Consciousness of Equilibrium is Nothingness. 27. But for [Prespacetime] there is neither tension nor Equilibrium. 28. The state of tensions is the state of ever-becoming. 29. Ever-becoming is endless-dying. 30. So the state of consciousness 
of objects is a state of ever-renewing promises that pass into death at the moment of fulfillment. 31. Thus when consciousness is attached to objects the agony of birth and death never ceases. 32. In the state of Equilibrium where birth cancels death the deathless Bliss of Nothingness is realized. 33. But [Prespacetime] is neither agony nor bliss. 34. Out of the Great Void, which is [Prespacetime], the Universe is creatively projected. 35 . The Universe as experienced is the created negation that ever resists. 36. The creative act is bliss, the resistance, unending pain. 37. Endless resistance is the Universe of experience, the agony of crucifixion. 38. Ceaseless creativeness is Nothingness, the Bliss beyond human conceiving. 39. But for [Prespacetime] there is neither creativeness nor resistance. 40. Ever-becoming and ever-ceasing-to-be are endless action. 41. When ever-becoming cancels the ever-ceasingto-be then Rest is realized. Ceaseless action is the Universe. 42. Unending Rest is Nothingness. 43. But [Prespacetime] is neither Action nor Rest. 44. When consciousness is attached to objects it is restricted through the forms imposed by the world-containing Space, by Time, and by Law. 44. When consciousness is disengaged from objects, Liberation from the forms of the worldcontaining Space, of Time, and of Law is attained. 45. Attachment to objects is consciousness bound within the Universe. 46. Liberation from such attachment is the State of unlimited Nirvanic Freedom. 47. But

\section{References}

Chalmers, D. The Conscious Mind (Oxford: Oxford University Press, 1996).

Faw, B. Review of TSC 2007. J. Conscious Stud., 2007; 14: 83-95.

Freeman, D. Acceptance speech for the Templeton Prize, Washington National Cathedral, May 9, 2000.

Hameroff, S. \& Penrose, R. Conscious events as orchestrated spacetime selections. J. Conscious Stud., 1996; 3: 36-53.

Horgan, J. The End of Science (New York: Broadway Bokks, 1996).

$\mathrm{Hu}, \mathrm{H}$. \& Wu, M. Spin-mediated consciousness. arXiv:quant-ph/0208068, 2002.
[Prespacetime] is neither bondage nor freedom. 48. [Prespacetime] may be symbolized by a SPACE that is unaffected by the presence or absence of objects, for which there is neither Time nor Timelessness, neither a worldcontaining Space nor a Spatial Void, neither Tension nor Equilibrium, neither Resistance nor Creativeness, neither Agony nor Bliss, neither Action nor Rest, and neither Restriction nor Freedom. 49. As [Prespacetime] is not to be identified with the Universe, so neither is It to be identified with any Self. 50. [Prespacetime] is not God, but the comprehender of all Gods, as well as of all lesser creatures. 51. [Prespacetime] is the Sole Reality upon which all objects and all selves depend and derive their existence. 52. [Prespacetime] comprehends both the Path of the Universe and the Path of Nothingness. 53. Beside [Prespacetime] there is none other. OM TAT SAT (Source: integralscience.org)

\section{Dedications \& Acknowledgments}

I dedicate this essay to my paternal grandmother Ernuu Wang whom I wish a speedy recovery and maternal grandmother Ernuu Zhou who has just left this world but lives in my heart and memory forever.

I am greatly thankful and deeply indebted to all the editors of journals and online archives who have allowed some or all of our recent writings to see the "daylight". Special thanks are also owed to my collaborator and wife, parents, children and others who in many ways known or unknown to me sustained me, supported me and encouraged me.

Hu, H. \& Wu, M. Photon induced non-local effect of general anesthetics on the brain. NeuroQuantology, 2006a; 4: 17-31.

$\mathrm{Hu}, \mathrm{H}$. \& Wu, M. Evidence of non-local physical, chemical and biological effects supports quantum brain. NeuroQuantology, 2006b; 4: 291-306.

Hu H. We have a dream. NeuroQuantology 2008; 1 : 75-79.

Kuhn, T. The Structure of Scientific Revolutions (Chicago: University of Chicago Press, 1962).

Planck, M. Interview with The Observer, London, Jan. 25, 1931.

Planck, M. Address on the 25th anniversary of the Kaiser-Wilhelm Gesellschaft, 10/11 January 1936. 
Hu, H., Reflection 2008: The State of Science, Religion and Consciousness

Planck, M. Speech at Florence, Italy, 1944.

Planck, M. Scientific Autobiography and Other Papers, trans. F. Gaynor (New York, 1949).

Rosenblum, B. \& Kuttner, F. Quantum Enigma (Oxford: Oxford University Press, 2006).
Smolin, L. The Trouble with Physics (New York: Houghton Mifflin Co., 2006).

Stapp. H. P. Mind, Matter and Quantum Mechanics (New York: Springer-Verlag, 1993).

Woit, P. Not Even Wrong (New York: Baisc Books, 2006). 